\title{
Cardioplegia prevents ischemia-induced transcriptional alterations of cytoprotective genes in rat hearts: A DNA microarray study
}

\author{
Steve J. Schomisch, BS, ${ }^{a}$ Deborah G. Murdock, PhD, ${ }^{b}$ Nasim Hedayati, MD, ${ }^{a}$ Joseph L. Carino, BS,
}

Edward J. Lesnefsky, MD, ${ }^{c}$ and Brian L. Cmolik, MD ${ }^{d}$

\section{eonly Additional material is available online.}

From the Division of Cardiothoracic Surgery, Case Western Reserve University, University Hospitals of Cleveland, ${ }^{\mathrm{a}}$ Cleveland, Ohio; the Department of Pediatrics, Vanderbilt University, ${ }^{\mathrm{b}}$ Nashville, Tenn; the Cardiology Section, Medical Service, Louis Stokes Department of Veterans Affairs Hospital and Case Western Reserve University, ${ }^{\mathrm{c}}$ Cleveland, Ohio; and the Division of Cardiothoracic Surgery, Louis Stokes Department of Veterans Affairs Hospital, Case Western Reserve University, University Hospitals of Cleveland, ${ }^{\mathrm{d}}$ Cleveland, Ohio.

Supported by the Jay L. Ankeney Endowment. Dr Lesnefsky was supported by grants 2RO1AG12447 and 1PO15885 from the National Institutes of Health and by the Medical Research Service, Department of Veterans Affairs. Dr Hedayati was an Allen Fellow supported by the Jay L. Ankeney Professorship in Cardiothoracic Surgery, Case Western Reserve University School of Medicine, Cleveland, Ohio.

Received for publication March 3, 2005; revisions received May 25, 2005; accepted for publication June 8, 2005.

Address for reprints: Brian L. Cmolik, MD, Cardiothoracic Surgery, University Hospitals of Cleveland, 11100 Euclid Ave, Cleveland, OH 44106-5011 (E-mail: blc3@case.edu).

J Thorac Cardiovasc Surg 2005;130:1151-8 $0022-5223 / \$ 30.00$

Copyright $\odot 2005$ by The American Association for Thoracic Surgery

doi:10.1016/j.jtcvs.2005.06.027
Background: Energy conservation and calcium homeostasis contribute to myocardial protection provided by hyperkalemic cardioplegia during ischemia. Complimenting these established mechanisms of protection, previous work suggested that activation of cytoprotective signaling pathways also contributes to reduced injury with cardioplegia. We proposed that cardioplegia would recruit cytoprotective pathways and investigated the transcriptional response of the heart after cardioplegia-protected ischemia compared with that after ischemia alone.

Methods: Isolated perfused rat hearts underwent 40 minutes of global ischemia alone or with St Thomas cardioplegia, followed by 120 minutes of reperfusion. The expression profiles of isolated RNA were determined by using Affymetrix microarrays and assessed by comparing cardioplegia-protected hearts and hearts undergoing unprotected ischemia with time-matched control hearts. The content of selected proteins was assessed by means of immunoblotting.

Results: Cardioplegia preserved the expression of multiple genes involved in carbohydrate and fatty acid metabolism, glycolysis, and electron transport compared with ischemia alone. The expression of the sodium-calcium exchanger and ryanodine receptor was preserved in line with the ability of cardioplegia to decrease calcium overload. The expression of multiple cytoprotective molecules, including protein-tyrosine kinase, calcineurin B, p38 mitogen-activated protein kinase, voltage-dependent anion channel, protein kinase $\mathrm{C} \epsilon$, heat shock protein 70 , and manganese superoxide dismutase all showed decreased expression in ischemia but were preserved to near nonischemic levels by cardioplegia.

Conclusion: Cardioplegia during ischemia maintained an expression profile similar to that seen in nonischemic hearts for genes involved in energy conservation, calcium homeostasis, and cytoprotective pathways, whereas ischemia alone did not. Exposing the transcriptional differences in cytoprotective genes during untreated and cardioplegia-treated ischemia provides valuable insight into an additional mechanism of cardioprotection induced by cardioplegia.

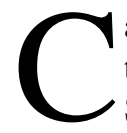

ardioplegic arrest is used to provide myocardial protection in the majority of the 686,000 patients who undergo cardiac surgical procedures in the United States each year. ${ }^{1}$ The arrested heart, although advantageous to the surgeon, remains susceptible to ischemic injury. Hyperkalemic cardioplegia (CP) is used to maintain diastolic arrest and provide myocardial protection by attenuating the progression of ischemic injury. Despite modifications to the formulation and route of administration, suboptimal myocardial protection remains a problem. The protective effect of $\mathrm{CP}$ is thought to be largely the result of conservation of cellular energy stores and preservation of calcium homeostasis. In addition to these accepted mechanisms of myocardial protection, previous work from our laboratory demon- 
strated that the myocardial protection provided by $\mathrm{CP}$ is substantially attenuated if intracellular signaling pathways involving protein kinase $\mathrm{C}$ ( $\mathrm{PKC}$ ) or tyrosine kinase are inhibited. ${ }^{2}$ Activation of these signaling kinases leads to cytoprotection and has been implicated in the robust cardioprotective response of ischemic preconditioning (IPC). This evolving appreciation of the key contribution of the activation of intracellular signaling pathways to myocardial protection $^{3}$ raises the question of whether similar mechanisms might contribute to the cardioprotection provided by $\mathrm{CP}$. To identify potential key contributing mechanisms involved in the cardioprotection of $\mathrm{CP}$, we used DNA microarray technology to profile the gene expression pattern of rat hearts subjected to ischemia and reperfusion alone compared with that seen in hearts subjected to CP-protected ischemia and reperfusion. The goal of this study was to evaluate transcriptional changes in genes related to previously known mechanisms of $\mathrm{CP}$ and to assess for evidence of the novel involvement of cytoprotective pathways.

\section{Materials and Methods}

All experiments were approved by the Case Western Reserve University Institutional Animal Care and Use Committee and conformed to the "Guide for the Care and Use of Laboratory Animals" prepared by the Institute of Laboratory Animal Resources, National Research Council and published by the National Academy Press (revised 1996).

\section{Isolated Rat Heart Preparation}

The isolated rat heart preparation was used as previously described. ${ }^{2}$ Male Sprague-Dawley rats (320-360 g) were anesthetized (heparin, 1000 units/kg administered intraperitoneally; pentobarbital, $100 \mathrm{mg} / \mathrm{kg}$ administered intraperitoneally). Hearts were excised, mounted on the Langendorff apparatus, and perfused with Krebs-Henseleit $(\mathrm{KH})$ buffer delivered at a perfusion pressure of $65 \mathrm{~mm} \mathrm{Hg}$. After collection of baseline data during the equilibration period, the hearts were randomized into one of the 3 study groups. Time-matched control hearts $(n=7)$ were perfused for 180 minutes. Hearts in the ischemic group $(n=7)$ were equilibrated for 20 minutes and then underwent 40 minutes of normothermic global ischemia, followed by 120 minutes of reperfusion with $\mathrm{KH}$ buffer. Hearts in the CP group $(n=7)$ were equilibrated for 17 minutes, perfused with St Thomas' Cardioplegia II $(\mathrm{NaCl}$, $110.0 \mathrm{mmol} / \mathrm{L} ; \mathrm{KCl}, 16.0 \mathrm{mmol} / \mathrm{L} ; \mathrm{CaCl}_{2}, 1.20 \mathrm{mmol} / \mathrm{L}$; $\mathrm{MgCl}_{2} * 6 \mathrm{H}_{2} \mathrm{O}, 16.0 \mathrm{mmol} / \mathrm{L}$; and $\mathrm{NaHCO}_{3}, 10.0 \mathrm{mmol} / \mathrm{L} ; \mathrm{pH}$ of $7.8 \pm 0.2, \mathrm{~T}=4^{\circ} \mathrm{C}$ ) for 3 minutes, and underwent 40 minutes of normothermic global ischemia, followed by 120 minutes of reperfusion with $\mathrm{KH}$ buffer. After 180 minutes, left ventricular (LV) tissue was excised and immediately frozen in liquid nitrogen. Three hearts from each group were used for RNA preparation, and 4 hearts were used independently for protein quantitation.

\section{Microarray Analysis}

Samples of total RNA were processed by the Gene Expression Array Core Facility at Case Western Reserve University.
RNA preparation. Total RNA was isolated from LV tissue by using Trizol Reagent (Invitrogen). RNA preparations from each group (ischemic, $\mathrm{CP}$, and control) were pooled $(\mathrm{n}=3)$, and their quality and quantity $(0.79,0.91$, and $1.10 \mu \mathrm{g}$ RNA/mg LV tissue) were assessed with spectrophotometry (260/280) and gel electrophoresis. Samples were cleaned and eluted by using a column from a Qiagen RNeasy kit (part no. 74106) precipitated with ammonium acetate and ethanol centrifuged, washed, and resuspended.

Synthesis of $\boldsymbol{c D N A}$. The Affymetrix protocol for cDNA synthesis was used. The reaction was primed by annealing an oligo-dT primer coupled to a $T_{7}$ RNA polymerase promoter to the RNA sample. RNA was reverse transcribed with Superscript II reverse transcriptase. Second-strand synthesis was carried out immediately in the presence of Escherichia coli DNA pol I, RNAse H, and DNA ligase; incubated in the presence of $\mathrm{T}_{4}$ DNA pol; and terminated with ethylenediamine tetraacetic acid (EDTA). The sample was cleaned (Qiagen cDNA clean-up column).

Synthesis of biotin-labeled complementary RNA. Complementary RNA was generated in an in vitro transcription reaction by using a BioArray High Yield ENZO kit (Affymetrix). Samples were mixed, centrifuged, and returned to the incubator every 40 minutes. In vitro transcription samples were cleaned (Qiagen RNA clean-up columns) and eluted. The quality was confirmed spectrophotometrically (260/280).

Fragmentation and hybridization to test array. Samples were fragmented (40 mmol/L Tris acetate [pH 8.1], $100 \mathrm{mmol} / \mathrm{L}$ potassium acetate, and $30 \mathrm{mmol} / \mathrm{L}$ magnesium acetate at $94^{\circ} \mathrm{C}$ for 35 minutes) and added to hybridization buffer (final concentrations: $100 \mathrm{mmol} / \mathrm{L}$ morpholinoethanesulfonic acid (MES); $1 \mathrm{~mol} / \mathrm{L}$ $\left[\mathrm{Na}^{+}\right] ; 20 \mathrm{mmol} / \mathrm{L}$ EDTA; $0.01 \%$ Tween $20 ; 0.1 \mathrm{mg} / \mathrm{mL}$ Herring sperm DNA; and $0.5 \mathrm{mg} / \mathrm{mL}$ acetylated bovine serum albumin) to improve hybridization to the oligonucleotide array. Eukaryotic hybridization controls (BioB, BioC, BioD, and cre; final concentrations of $1.5,5,25$, and $100 \mathrm{pmol} / \mathrm{L}$, respectively) and control oligonucleotide $(50 \mathrm{pmol} / \mathrm{L})$ were added to the cocktail. The hybridization cocktail was denatured $\left(99^{\circ} \mathrm{C}\right.$ for 5 minutes), transferred to the test array, and incubated $\left(42^{\circ} \mathrm{C}\right.$ for 16 hours), and the hybridization cocktail was removed. The array was washed, stained, and scanned for background fluorescence and expression levels of control oligonucleotides by using Affymetrix Microarray Suite software.

Hybridization of fragmented samples to species microarray. Sample hybridization cocktails were thawed $\left(45^{\circ} \mathrm{C}\right)$ and centrifuged. The Affymetrix chip arrays (RG-U34A, part no. 510338), containing probe sets for more than 7000 known genes, were equilibrated to room temperature. Sample cocktails were introduced into the chamber of the preconditioned chips and incubated ( $45^{\circ} \mathrm{C}$ for 16 hours). The chips were washed, stained, and scanned with an Agilent Gene Array scanner 2000 driven by Affymetrix MicroArray Suite 5.0. Genes with unknown products or duplicate entries were omitted. Functional or biologic classification was determined from the Affymetrix database, the PubMed database, or both.

Statistical analysis of species microarray. Scanned images were analyzed with Affymetrix MAS 5.0 software. For complete description of the statistical algorithms, refer to the Statistical Algorithm Description Document available from Affymetrix. The following tunable parameters were used: $\alpha 1=0.04$ and $\alpha 2=$ 
0.06 for single-array analysis, and $\tau=0.015, \gamma 1 \mathrm{~L}=0.0025, \gamma 1 \mathrm{H}$ $=0.0025, \gamma 2 \mathrm{~L}=0.003$, and $\gamma 2 \mathrm{H}=0.003$ for comparison analysis. Statistical significance is determined by query of 3 parameters: detection, fold change, and change. To be regarded as increased in the treated sample compared with the control, detection was "P" (present) or "M" (marginal), fold change was 2 or more, and change was "I" (increased). For decreases, detection in the sample was "P" or " $M$," fold change was -2 or less, and change was D (decreased). The change algorithm uses the Wilcoxon signed-rank test with corresponding cutoffs of $\gamma(P<.0025$ vs control).

\section{Western Analysis}

Frozen ventricular tissue was placed in buffer (Tris- $\mathrm{HCl}, 50$ $\mathrm{mmol} / \mathrm{L}$ [pH 7.4]; sodium orthovanadate, $0.1 \mathrm{mmol} / \mathrm{L}$; sodium fluoride, $50 \mathrm{mmol} / \mathrm{L}$; sucrose, $150 \mathrm{mmol} / \mathrm{L}$; phenylmethylsulfonyl fluoride, $1 \mathrm{mmol} / \mathrm{L}$; EDTA, $5 \mathrm{mmol} / \mathrm{L}$; ethyleneglycol-bis- $(\beta$ aminoethylether)-N,N, $\mathrm{N}^{\prime}, \mathrm{N}^{\prime}$ tetraacetic acid, $2 \mathrm{mmol} / \mathrm{L} ; 0.2 \%$ Triton $\mathrm{X}-100$, Sigma protease inhibitor cocktail 1:200 [producing final concentrations of 4-(2-aminoethyl)benzenesulfonylfluoride $\mathrm{HCl}$ (AEBSF), $500 \mu \mathrm{mol} / \mathrm{L}$; Aprotinin, $0.4 \mu \mathrm{mol} / \mathrm{L}$; Leupeptin, 10 $\mu \mathrm{mol} / \mathrm{L}$; Bestatin, $18 \mu \mathrm{mol} / \mathrm{L}$; Pepstatin, $7.5 \mu \mathrm{mol} / \mathrm{L} ; \mathrm{E}-64,7$ $\mu \mathrm{mol} / \mathrm{L}]$ ) and homogenized (Polytron, 2 bursts of 30 seconds, speed 5). The lysate was mixed on ice for 60 minutes. The solubilized proteins were centrifuged at $360 \mathrm{~g}$ for 10 minutes, and the resulting supernatant was assayed for total protein concentration by using the Bradford method. Total protein $(15 \mu \mathrm{g})$ was separated by means of sodium dodecylsulfate-polyacrylamide gel electrophoresis and transferred to polyvinylidene difluoride membrane. Nonspecific binding was blocked with 5\% nonfat milk, and the membrane was incubated with primary antibody (anti-p38, mouse monoclonal sc-7972, Santa Cruz Biotechnology Inc; antiprotein-tyrosine kinase [anti-JAK2], rabbit polyclonal, Upstate Biotechnology; anti-sodium-calcium exchanger, rabbit polyclonal, Swant). The membrane was washed and incubated with the appropriate horseradish peroxidase-linked secondary antibody, washed, and then incubated with a chemiluminescent agent (Luminol, Santa Cruz Biotechnology). Photographic film was exposed to the chemiluminescence, and the bands were quantified by means of densitometry (Scion Image, Scion Corp) as normalized to a control lysate.

\section{Statistical Analysis of Left Ventricular Developed Pressure Recovery, Lactate Dehydrogenase Release, and Protein Content}

Data are expressed as means \pm SEM. One-way analysis of variance with the Tukey post-hoc test were performed on left ventricular developed pressure (LVDP) recovery, lactate dehydrogenase $(\mathrm{LDH})$ release, and protein content.

\section{Results}

\section{LVDP and LDH}

Time-matched control hearts performed as expected for this model, with preserved LVDP after 180 minutes. Ischemic hearts showed decreased recovery of function compared with control hearts. CP treatment before ischemia markedly protected against the decrease in LVDP (Figure 1). Ischemic
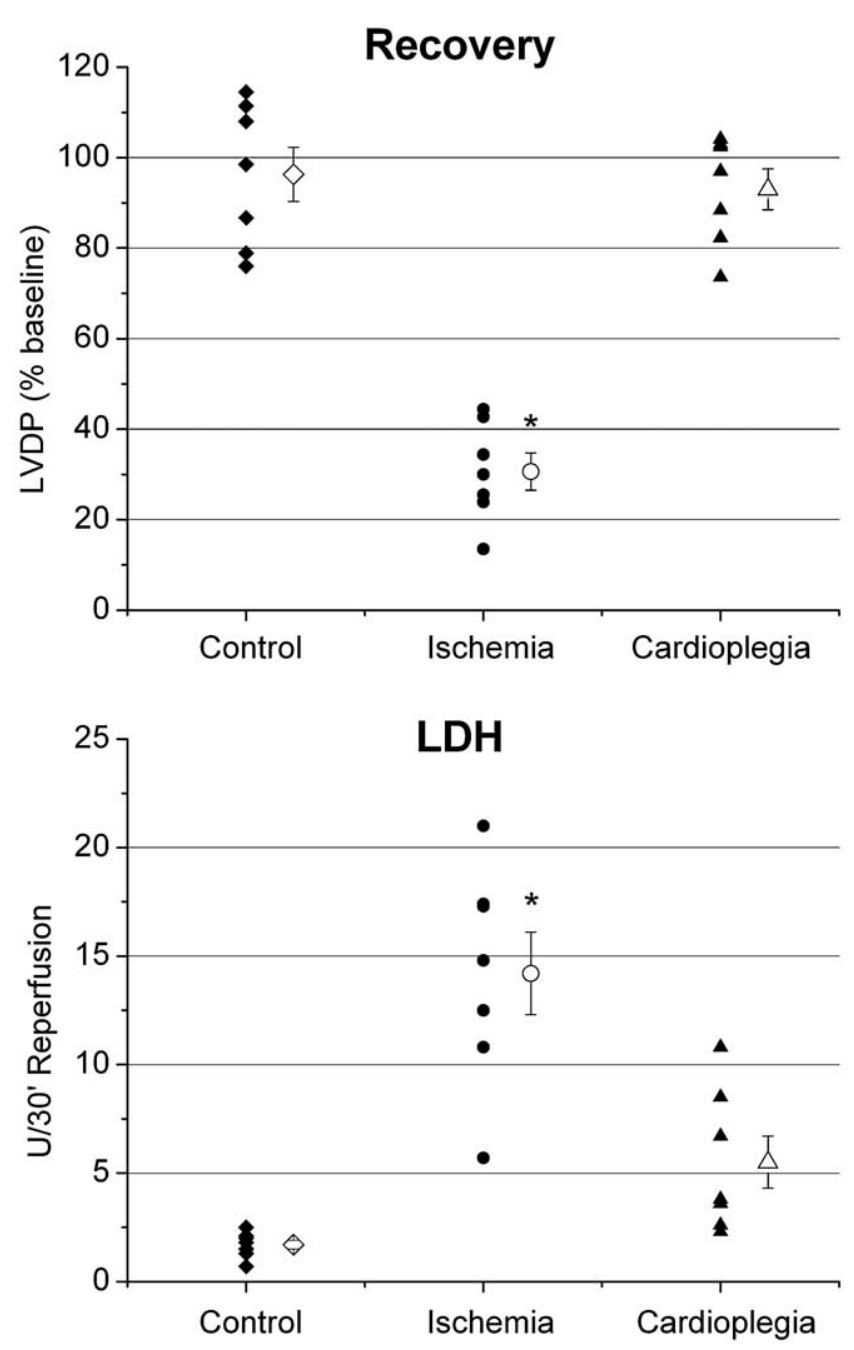

Figure 1. Recovery of function (top) at $\mathbf{1 8 0}$ minutes and LDH release during minutes 60 through 90 . LVDP, Left ventricular developed pressure; $L D H$, lactate dehydrogenase. ${ }^{*} P<.001$ versus control or cardioplegia groups.

hearts showed a significant increase in LDH release compared with that seen in nonischemic control hearts, as well as compared with hearts undergoing CP-treated ischemia (Figure 1). Values for LVDP and LDH release are comparable with those obtained previously in this model. ${ }^{2}$

\section{Expression Profile}

The gene expression profile of rat hearts subjected to $\mathrm{CP}$ protected ischemia and reperfusion was compared with the profile in hearts subjected to ischemia and reperfusion alone and with the time control group. The number of genes with 2 -fold or greater change was reduced by removing probes with unknown products and duplicates (multiple probe sets that hybridize to the same product). After this reduction, 
TABLE 1. Biologic function of genes with decreased expression after ischemia but preserved with cardioplegia

\begin{tabular}{|c|c|}
\hline No. of genes & Function/description \\
\hline \multicolumn{2}{|c|}{ Energy/metabolism } \\
\hline 2 & Acetyl CoA synthesis from pyruvate \\
\hline 1 & ATP metabolism \\
\hline 7 & Carbohydrate metabolism \\
\hline 5 & Electron transport/energy production \\
\hline 7 & FA metabolism \\
\hline 7 & Other \\
\hline \multicolumn{2}{|c|}{ Calcium regulation } \\
\hline 2 & Calcium regulation \\
\hline 1 & Calcium channel binding \\
\hline 2 & Calcium binding \\
\hline \multicolumn{2}{|c|}{ Immune/inflammatory } \\
\hline 4 & Immune/inflammatory \\
\hline \multicolumn{2}{|c|}{ Cytoprotective-ischemia/IPC/stress } \\
\hline 4 & Stress response \\
\hline 3 & $\begin{array}{l}\text { Glutathione synthesis/oxidative } \\
\text { stress }\end{array}$ \\
\hline 3 & Heat shock/chaperone \\
\hline 2 & Oxidative stress \\
\hline 5 & Other \\
\hline \multicolumn{2}{|l|}{ Transcription } \\
\hline 11 & Transcription \\
\hline \multicolumn{2}{|l|}{ Other } \\
\hline 9 & Protein transport \\
\hline 4 & Adhesion molecule \\
\hline 4 & Angiogenesis \\
\hline 4 & Cytoskeletal \\
\hline 2 & $\mathrm{Mg}^{2+}$-dependent phosphatase \\
\hline 3 & Growth \\
\hline 2 & Cell cycle \\
\hline 19 & Other \\
\hline
\end{tabular}

A complete list is available online in Table E2. CoA, Coenzyme A; ATP, adenosine triphosphate; $F A$, fatty acid; IPC, ischemic preconditioning.

146 genes were expressed with a 2-fold or greater change in the unprotected ischemic group that was unchanged in the $\mathrm{CP}$-protected ischemic group compared with the nonischemic control group. With the same 2-fold cutoff point, 18 differences were found to be unique to the CP-treated group but not to the ischemia group compared with the control group. Thirty-three genes demonstrated 2-fold or greater change in both the ischemia and CP-treated groups compared with the control group. Most of the changes unique to the ischemic group demonstrated decreased expression (112/146), whereas changes unique to CP treatment predominantly reflected increased expression (11/18).

Genes with increased expression in the ischemic group but not in the CP-treated group represent products that display a diverse array of functions (Table E1) and include some potentially related to cardioprotection. Among the genes exhibiting decreased expression after ischemia but that were not diminished with $\mathrm{CP}$ protection (Tables 1 and E2) are 29 genes involved in carbohydrate metabolism, fatty acid metabolism, glycolysis, electron transport, or other cellular processes involved in energy production. Five genes involved in calcium regulation or calcium binding, including the sodium-calcium exchanger ( $\mathrm{NCx}$ ) and ryanodine receptor, had decreased expression after ischemia unless protected with CP. Genes for proteins involved in cytoprotection, including JAK2, calcineurin B, p38 mitogen-activated protein kinase (MAPK), voltage-dependent anion channel, PKC-binding protein enigma, PKC- $\epsilon$, heat shock protein 70-related gene and precursor, and mitochondrial manganese superoxide dismutase, also did not maintain baseline levels of their transcripts after ischemia unless first protected with $\mathrm{CP}$.

Genes exhibiting decreased expression in both the ischemia and CP-treated groups were predominantly those that function in the inflammatory or immune responses, notably tumor necrosis factor $\alpha$ and interleukin 1 (Table E3). The genes with increased expression after ischemia in both the untreated and $\mathrm{CP}$-treated groups compared with the control group were few and included heat shock protein 70 (Table E3).

Of the few genes altered by CP-protected ischemia, 3 related to the immune-inflammatory response, including interleukin 18, demonstrated decreased expression (Table 2). Genes with increased expression in CP treatment but not ischemia displayed seemingly diverse functions, with the largest change being an increase in a heat shock protein (Table 2).

\section{Content of Selected Proteins}

Protein content was evaluated by means of Western analysis and compared with transcript levels to validate selected results observed at the level of gene translation. Western analysis revealed a significantly reduced content of p38 MAPK in untreated ischemic hearts compared with either control $(P<.001)$ or $\mathrm{CP}$-treated hearts $(P<.001$, Figure $2)$. The protein content of JAK2 was also reduced in ischemic hearts compared with control hearts $(P=.009)$ or hearts undergoing $\mathrm{CP}$-treated ischemia $(P=.019)$. Differences between groups in $\mathrm{NCx}$ protein content, however, were not significant (data not shown).

\section{Discussion}

This study was designed to investigate potential mechanisms whereby $\mathrm{CP}$ provides myocardial protection by evaluating changes that occur at the level of transcription. Relative transcript abundance was evaluated by using the microarray approach. The alterations in gene expression caused by ischemia alone or ischemia protected with $\mathrm{CP}$ was assessed in isolated rat hearts perfused by means of the Langendorff method. 
TABLE 2. Changed expression with cardioplegia but not ischemia

\begin{tabular}{|c|c|c|c|c|}
\hline Gene no. & Ischemia vs C & CP vs C & Gene product & Function-description \\
\hline \multicolumn{5}{|c|}{ Immune-inflammatory } \\
\hline U65217 & -1.2 & -3.5 & MHC class II antigen RT1.B beta & Immune/inflammatory \\
\hline U77777 & NC & -2.1 & Interleukin 18 & Immune/inflammatory \\
\hline X54250 & -1.9 & -2.0 & HIV type I enhancer-binding protein 1 & Immune/inflammatory \\
\hline \multicolumn{5}{|c|}{ Cytoprotective-ischemia/IPC/stress } \\
\hline U53922 & 1.7 & 2.3 & DnaJ-like protein (RDJ1) & Heat shock/chaperone \\
\hline AA108277 & 1.5 & 5.7 & similar to Heat shock protein (hsp-E7l) & Heat shock/chaperone \\
\hline \multicolumn{5}{|c|}{ Transcription } \\
\hline L20681 & $\mathrm{NC}$ & 2.0 & ETS-1 proto-oncogene & Transcription \\
\hline D26307 & -1.7 & 2.1 & jun-D & Transcription \\
\hline \multicolumn{5}{|l|}{ Other } \\
\hline D12769 & 1.6 & 2.1 & Kruppel-like factor 9 & Growth and development \\
\hline X06769 & 1.9 & 2.3 & $c$-fos & Growth and development \\
\hline U75397 & 1.9 & 2.3 & Krox-24 & Growth and development \\
\hline AF034899 & NC & -2.5 & Olfactory receptor-like (SCR D-9) & Chemoreceptor \\
\hline AF063102 & -1.2 & -2.3 & CIRL-2 & $\alpha$-Latrotoxin receptor \\
\hline D10757 & -1.5 & -2.3 & Proteasome subunit, $\beta-9$ & Protein catabolism \\
\hline L35558 & -1.7 & -2.1 & Glutamate/aspartate transporter & Glutamate signaling \\
\hline U49099 & 1.9 & 2.0 & Cis-Golgi p28 (p28) & Protein transport \\
\hline M94918 & 1.7 & 2.0 & Hemoglobin beta chain & Oxygen transport \\
\hline Y13275 & NC & 2.0 & Transmembrane 4 family member 3 & Blood coagulation \\
\hline AF030088 & NC & 2.0 & Homer & Glutamate signaling \\
\hline
\end{tabular}

Values represent fold change. Negative designates decrease. $C$, Control; $C P$, cardioplegia; $M H C$, major histocompatibility complex; $N C$, no change; $C I R L-2$, calcium-independent receptor of alpha-latrotoxin-2.

The Langendorff model chosen, using 40 minutes of normothermic global ischemia, eliminates the confounding effects of hypothermic ischemia and was shown to provide good resolution between treatments in functional end points (Figure 1). ${ }^{2}$ Microarray analysis in the 3 groups revealed differences corroborating the known protective mechanisms of CP, namely energy conservation and calcium homeostasis. The transcriptional data also support the preservation of a nonischemic phenotype by cardioplegia, a new observation.

It is important to recall that although collectively ischemia is damaging to cardiac function, the changes in the expression of individual genes is not necessarily detrimental. Likewise, although CP protection improves function, each of the changes in individual gene expression levels is not necessarily beneficial. The stimulus of ischemia or CP might evoke a combination of responses activating adaptive or protective mechanisms, as well as disrupting normal cell functions. A comparison of gene expression levels between ischemia and $\mathrm{CP}$-protected ischemia therefore might provide clues as to the mechanism of cardioprotection, as well as its limitations. Additionally, gene expression studies are not definitive but are rather preliminary studies to focus further investigation.

The greatest disruption to the normal transcription process occurred in the untreated ischemic group, with 133 genes demonstrating a 2 -fold or greater decrease in expres- sion. CP treatment limited the decreased transcript content to merely 28 genes. The ability of $\mathrm{CP}$ treatment to maintain expression levels nearer to control for genes otherwise altered by ischemia suggests that $\mathrm{CP}$, in general, preserves a nonischemic transcriptional profile and is likely to maintain a nonischemic phenotype. The protein content data shown in Figure 2 support this notion.

The ability of CP treatment to maintain transcription levels of genes involved in carbohydrate metabolism, fatty acid metabolism, glycolysis, electron transport, and calcium homeostasis suggests mechanisms of $\mathrm{CP}$ involving the relative conservation of energy and prevention of cellular calcium overload. The $\mathrm{NCx}$ and ryanodine receptor are important regulators of $\mathrm{Ca}^{2+}$ homeostasis. Increased expression of $\mathrm{NCx}$ and ryanodine receptor has been demonstrated as an adaptive response to low-flow ischemia. ${ }^{4} \mathrm{Al}-$ though we were unable to demonstrate differences in the protein content for $\mathrm{NCx}$, here we show increased gene expression in CP-protected ischemia compared with that in ischemia alone for these important regulators of calcium homeostasis.

Assessing the changes that occur to gene expression by cardioplegia protection but not by ischemia alone (Table 2) arguably would appear most pertinent to the mechanism of cardioplegia. Surprisingly, this category contained relatively few genes. Furthermore, the magnitude of change was small, with just one gene exhibiting greater than a 3-fold 

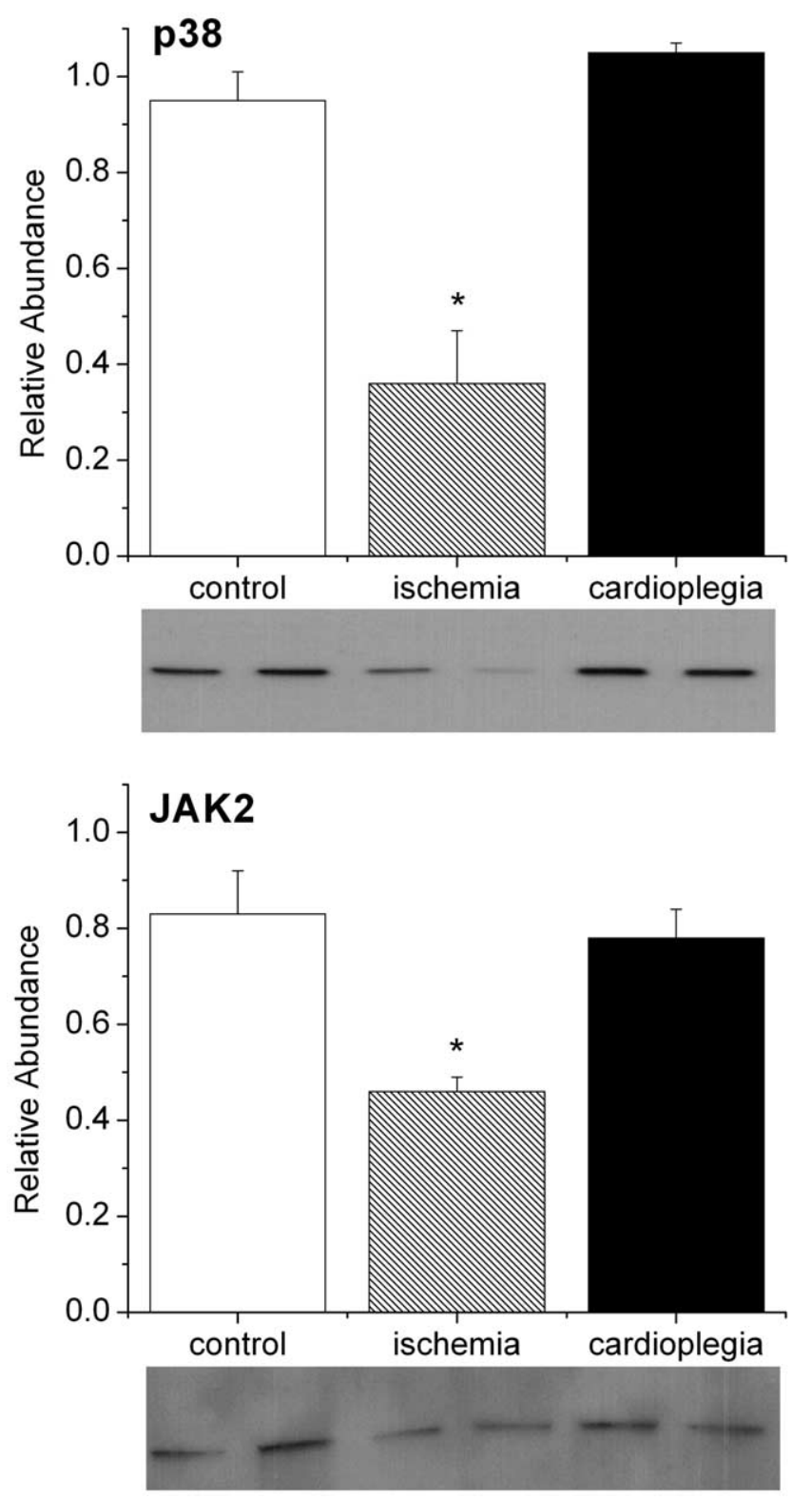

Figure 2. Myocardial abundance of p38 mitogen-activated protein kinase (p38, top) and protein-tyrosine kinase (JAK2, bottom) in time-matched control (open bar), ischemic (hatched bar), or cardioplegia-treated (filled bar) hearts after 2 hours of reperfusion or equivalent time for control hearts $(n=4)$. Units are relative to a common, nonischemic heart value set at $\mathbf{1 . 0 0}$. Western blotting shows representative hearts $(n=2)$ for each group. ${ }^{*} P<.05$ compared with control or cardioplegia-treated hearts.

increase and one with a greater than 3-fold decrease. This finding refutes our hypothesis that cardioplegia would activate numerous cytoprotective pathways but rather suggests that the cardioprotection of cardioplegia might be less a factor of transcriptional changes induced by the treatment

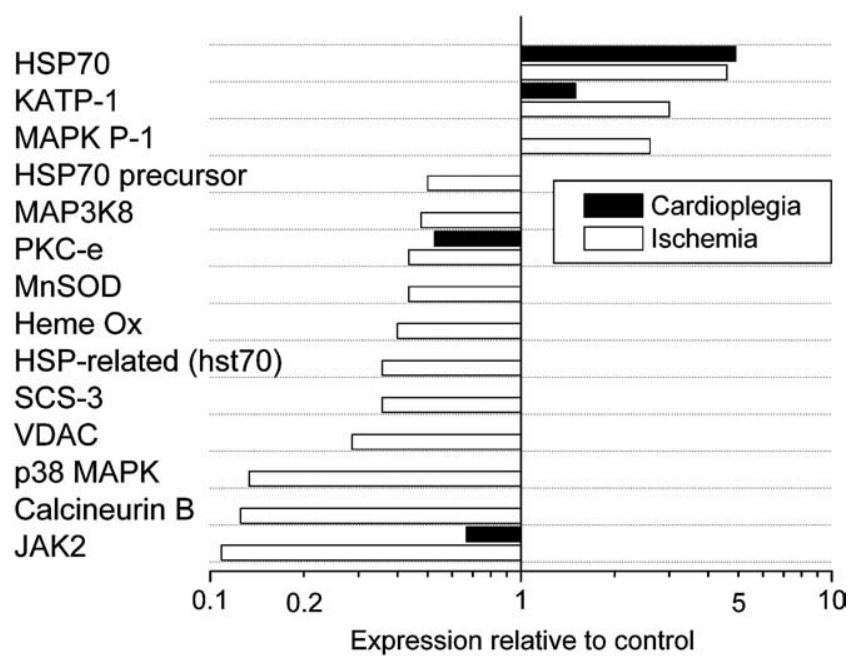

Figure 3. Cardioplegia preserves expression of genes with cytoprotective function. Open bars represent unprotected ischemia, and filled bars represent cardioplegia-protected ischemia. Data are displayed relative to control values of 1 , such that a 2 -fold decrease $(-2)$ is equivalent to 0.5. HSP70, 70-kd Heat shock protein; KATP-1, adenosine triphosphate-sensitive potassium channel uKATP-1; MAPK P-1, mitogen-activated protein kinase phosphatase 1; HSP70 precursor, 70-kd heat shock protein precursor; MAP3K8, serine-threonine protein kinase (Map3k8); PKC-e, protein kinase C $\epsilon$; MnSOD, manganese superoxide dismutase; Heme Ox, heme oxygenase; HSP-related (hst70), heat shock protein-related gene hst70; $S C S$-3, suppressor of cytokine signaling 3; VDAC, voltage-dependent anion channel; p38 MAPK, p38 mitogen-activated protein kinase; JAK2, protein-tyrosine kinase.

and more a function of minimizing ischemia-induced alterations in transcription.

Of particular focus in this study were changes in genes known to be involved in cytoprotective mechanisms, including IPC. As with other cluster groups, CP-protected ischemia produced expression levels closer to baseline levels than did unprotected ischemia for genes related to cytoprotective pathways (Figure 3). Interestingly, several genes with decreased expression in ischemia but preserved with CP treatment have previously been shown to have roles in the cardioprotective response during ischemia and reperfusion (Tables 1 and E2). These include JAK $2,{ }^{6}$ calcineurin $\mathrm{B},{ }^{7,8}$ p38 MAPK, ${ }^{9}$ voltage-dependent anion channel, ${ }^{3}$ PKCbinding protein enigma, ${ }^{10} \mathrm{PKC}-\epsilon,{ }^{11}$ heat shock protein $70-$ related gene and precursor, ${ }^{12}$ and manganese superoxide dismutase. ${ }^{13}$ Although the precise role for each of these gene products is unclear, the evidence implicating them in ischemia or cardioprotective mechanisms makes the alterations observed in our study intriguing. Repressed gene expression of these mediators after ischemia, as we have 
demonstrated for p38 and JAK2 (Figure 2), might indicate the cell's inability to maintain appropriate content of these peptides and thus contribute to injury. The ability of the CP-protected heart to maintain expression levels much closer to the baseline levels suggests mechanisms of cardioplegia-induced protection that were previously unknown.

Genes with increased expression in ischemia but not CP compared with control values (Table E1) included the adenosine triphosphate-sensitive potassium channel and MAPK phosphatase 1, proteins involved in modulation of cardiac injury during ischemia. Once thought to be the final step in the signaling cascade of IPC, ${ }^{5}$ the opening of mitochondrial adenosine triphosphate-sensitive potassium channels is one of many important alterations in mitochondrial proteins that might contribute to cardioprotection. ${ }^{3}$ Exactly which members of the MAPK cascades are involved and how they function remains unclear. However, much evidence supports their involvement in the cardioprotection of IPC., Increased expression after ischemia of proteins related to these mechanisms could be indicative of a response by the cell to upregulate their production in an attempt to attenuate ischemic damage. If this upregulation is beneficial and yet deficient in the CP-treated group, this finding might provide an opportunity to improve the protection provided by CP. To validate the transcriptional changes for select genes and to assess the potential physiologic effect, we quantified 3 proteins of interest. The protein content of p38 MAPK and JAK2 correlated with the observed change in transcription (Figure 2). The smaller change in transcript levels of $\mathrm{NCx}$ was not reflected in protein content (data not shown). Further characterization of these changes by measuring abundance of specific transcripts and protein activity might be beneficial to determine their role in cardioprotection.

Also noteworthy is the disproportionate number of genes involved in the inflammatory response, which displayed decreased expression in ischemia and CP (Table E3). Recognizing the relationship of ischemia to oxidative stress and of the latter to inflammation, we anticipated increased expression for many inflammatory markers in the ischemic group but not in the $\mathrm{CP}$ group. Perhaps this represents the extent of dysfunction caused in ischemia and in CP treatment before ischemia or occurs because of the use of the buffer-perfused heart as the model of experimental ischemia. This finding nonetheless suggests that the heightened inflammatory response prevalent after cardiopulmonary bypass (CPB) might not occur as a result of $\mathrm{CP}$ but rather is activated by other factors. The unique expression profile in human atrial tissue after $\mathrm{CPB}$ and cardioplegic arrest ${ }^{14}$ provides valuable data to support this statement. These investigators noted increased expression of inflammatory genes after CPB. Our observation of predominantly decreased inflammatory genes in the isolated perfused heart suggests that the increases observed in the clinical setting might occur because of one or more of the additional factors associated with the clinical cardiac surgical setting, including perhaps the CPB circuit, hypothermia, surgical trauma, anesthesia, or preexisting ischemia. Additionally, induced genes unique to the clinical study might be reflective of differences between analysis of LV tissue from an isolated rat heart and atrial tissue from CPB surgery or merely limitations of the microarray technique. Future studies will be needed to delineate these differences.

The current study evaluated differences in the gene expression pattern between hearts subjected to ischemia alone or hearts protected with hyperkalemic CP before ischemia. Ischemia altered the pattern of expression to a much greater extent in untreated hearts than in hearts first protected with $\mathrm{CP}$, suggesting that $\mathrm{CP}$-protected ischemia tends to preserve the nonischemic transcriptional phenotype. Many of the genes exhibiting decreased expression caused by ischemia alone are important in energy production and calcium homeostasis, which is consistent with proposed mechanisms of CP-induced myocardial protection. In addition, the cardioprotection provided by $\mathrm{CP}$ maintains cytoprotective peptides reminiscent of IPC. The novel concept that cardioplegia can prevent ischemic disruptions to the transcriptional processes of many genes, including those involved in cytoprotection, is worthy of consideration for advancing myocardial protective strategies during cardiac surgery.

We appreciate the assistance of Ms Michelle Quicci in preparation of the RNA and Patrick Leahy, PhD, in conducting the microarray analysis. We also thank Christine Moravec, $\mathrm{PhD}$, for helpful discussions and review of the manuscript and Mark Schluchter, PhD, for review of the statistical methods.

\section{References}

1. American Heart Association. Heart disease and stroke statistics-2003 update. Dallas, Tex: American Heart Association; 2002.

2. Hedayati N, Schomisch SJ, Carino JL, Sherwood JT, Lesnefsky EJ, Cmolik BL. Cardioprotection by St. Thomas' solution is mediated by protein kinase C and tyrosine kinase. J Surg Res. 2003;113:121-7.

3. Murphy E. Primary and secondary signaling pathways in early preconditioning that converge on the mitochondria to produce cardioprotection. Circ Res. 2004;94:7-16.

4. Assayag P, Charlemagne D, Marty I, de Leiris J, Lompre AM, Boucher $F$, et al. Effects of sustained low-flow ischemia on myocardial function and calcium-regulating proteins in adult and senescent rat hearts. Cardiovasc Res. 1998;38:169-80.

5. Cohen MV, Baines CP, Downey JM. Ischemic preconditioning: from adenosine receptor to $\mathrm{K}_{\mathrm{ATP}}$ channel. Annu Rev Physiol. 2000;62:79109.

6. Bolli R, Dawn B, Xuan Y. Role of the JAK-STAT pathway in protection against myocardial ischemia/reperfusion injury. Trends Cardiovasc Med. 2003;13:72-9.

7. Molkentin JD. Calcineurin, mitochondrial membrane potential, and cardiomyocyte apoptosis. Circ Res. 2001;88:1220-2.

8. Lakshmikuttyamma A, Selvakumar P, Kakkar R, Kanthan R, Wang R, Sharma RK. Activation of calcineurin expression in ischemiareperfused rat heart and human ischemic myocardium. J Cell Biochem. 2003;90:987-97. 
9. Steenbergen C. The role of p38 mitogen-activated protein kinase in myocardial ischemia/reperfusion injury; relationship to ischemic preconditioning. Basic Res Cardiol. 2002;97:276-85.

10. Maeno-Hikichi Y, Chang S, Matsumura K, Lai M, Lin H, Nakagawa $\mathrm{N}$, et al. A PKC- $\epsilon$-ENH-channel complex specifically modulates $\mathrm{N}$ type $\mathrm{Ca}^{2+}$ channels. Nat Neurosci. 2003;6:468-75.

11. Baines CP, Zhang J, Wang G, Zheng Y, Xiu JX, Cardwell EM, et al. Mitochondrial PKC $\epsilon$ and MAPK form signaling modules in the murine heart. Circ Res. 2002;90:390-7.

12. Hampton CR, Shimamoto A, Rothnie CL, Griscavage-Ennis J, Chong
A, Dix DJ, et al. HSP70.1 and -70.3 are required for late-phase protection induced by ischemic preconditioning of mouse hearts. Am J Physiol Heart Circ Physiol. 2003;285:H866-74.

13. Marczin N, El-Habashi N, Hoare GS, Bundy RE, Yacoub M. Antioxidants in myocardial ischemia-reperfusion injury: therapeutic potential and basic mechanisms. Arch Biochem Biophys. 2003; 420:222-36.

14. Ruel M, Bianchi C, Khan T, Xu S, Liddicoat J, Voisine P, et al. Gene expression profile after cardiopulmonary bypass and cardioplegic arrest. J Thorac Cardiovasc Surg. 2003;126:1521-30. 
TABLE E1. Increased expression with ischemia but unchanged with cardioplegia

\begin{tabular}{|c|c|c|c|c|}
\hline \multicolumn{3}{|c|}{ Ischemia } & Gene product & Function/description \\
\hline \multicolumn{5}{|c|}{ Energy/metabolism } \\
\hline D16102 & 5.7 & NC & $\begin{array}{l}\text { ATP-stimulated glucocorticoid-receptor } \\
\text { transl promoter }\end{array}$ & Carbohydrate metabolism \\
\hline M33648 & 2.6 & NC & $\begin{array}{l}\text { 3-Hydroxy-3-methylglutaryl-CoA } \\
\text { synthase }\end{array}$ & Acetyl CoA metabolism \\
\hline U07971 & 2.5 & 1.7 & L-Arginine-glycine amidinotransferase & Amino acid metabolism \\
\hline S69874 & 2.1 & NC & Cutaneous fatty acid-binding protein & FA metabolism \\
\hline X51529 & 2.0 & NC & Platelet phospholipase $A_{2}$ & FA metabolism \\
\hline L46791 & 2.5 & NC & Cholesterol esterase & Carboxylesterase activity \\
\hline \multicolumn{5}{|c|}{ Calcium regulation/contractility } \\
\hline D29646 & 2.0 & NC & ADP-ribosyl cyclase (CD38) & Calcium regulation \\
\hline X52840 & 2.3 & NC & Myosin regulatory light chain & Contractility \\
\hline \multicolumn{5}{|c|}{ Immune/Inflammatory } \\
\hline L23128 & 2.1 & 1.7 & MHC class I & Immune/inflammatory \\
\hline M64986 & 2.0 & 1.2 & Amphoterin & Immune/inflammatory \\
\hline \multicolumn{5}{|c|}{ Cytoprotective-ischemia/IPC/stress } \\
\hline D42145 & 3.0 & 1.5 & $\begin{array}{l}\text { ATP-sensitive potassium channel } \\
\text { uKATP-1 }\end{array}$ & Stress/IPC/cardioprotection \\
\hline S81478 & 2.6 & NC & MAP kinase phosphatase 1 & Stress induced \\
\hline L01702 & 2.6 & 1.6 & Protein-tryosine-phosphatase (LRP) & PKC-dependent Src act \\
\hline K01932 & 2.1 & NC & glutathione $S$-transferase $Y_{c}$ subunit & Glutathione synthesis/stress \\
\hline \multicolumn{5}{|c|}{ Transcription } \\
\hline Z17223 & 3.0 & 1.9 & Gax protein & Transcription \\
\hline AF000942 & 2.6 & 1.4 & $\mathrm{Id} 3 \mathrm{a}$ & Transcription \\
\hline X61296 & 2.5 & NC & L1 retroposon, ORF2 & Transcription \\
\hline U17254 & 2.5 & NC & $\begin{array}{l}\text { Immediate early gene transcription } \\
\text { factor NGFI-B }\end{array}$ & Transcription \\
\hline U91679 & 2.1 & NC & ETS domain transcription factor Pet- 1 & Transcription \\
\hline \multicolumn{5}{|c|}{ 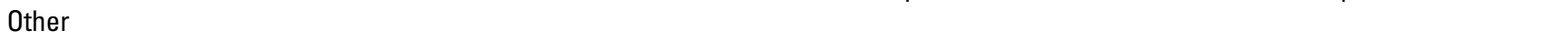 } \\
\hline X59859 & 2.3 & NC & decorin & Extracellular matrix org \\
\hline Y13714 & 2.0 & NC & osteonectin & Extracellular matrix org \\
\hline U75928 & 2.0 & 1.3 & SPARC & Extracellular matrix org \\
\hline J04035 & 2.0 & 1.4 & Tropoelastin & Extracellular matrix org \\
\hline X55183 & 2.8 & 1.9 & Schwannoma-derived growth factor & Growth factor \\
\hline M81183 & 2.3 & 1.4 & Insulin-like growth factor I & Growth factor \\
\hline M31837 & 2.0 & NC & $\begin{array}{l}\text { Insulin-like growth factor-binding } \\
\text { protein (IGF-BP3) }\end{array}$ & Growth factor \\
\hline J05495 & 2.5 & 1.6 & Gal/GalNAc-specific lectin & Binds to $\mathrm{Gal} / \mathrm{GalNAc}$ \\
\hline U82623 & 3.0 & NC & RalA binding protein 1 & Protein transport \\
\hline M96601 & 2.3 & NC & Taurine transporter & Neuroprotective \\
\hline D14014 & 2.3 & NC & Cyclin D1 & Cell-cycle regulation \\
\hline $\mathrm{X} 71127$ & 2.1 & 1.3 & Complement protein C1q $\beta$-chain & Complement activation \\
\hline V01227 & 2.0 & 1.4 & $\alpha$-Tubulin & Microtubule movement \\
\hline U42627 & 2.0 & NC & $\begin{array}{l}\text { Dual-specificity protein tyrosine } \\
\text { phosphatase (rVH6) }\end{array}$ & Phosphatase \\
\hline X12957 & 2.6 & NC & $\gamma$ Crystallin gene cluster & Eye lens proteins \\
\hline
\end{tabular}

Values are fold changes. $C$, Control; $C P$, cardioplegia; $N C$, no change; $A T P$, adenosine triphosphate; $C o A$, coenzyme $A ; F A$, fatty acid; $A D P$, adenosine diphosphate; $M H C$, major histocompatibility complex; IPC, ischemic preconditioning; $M A P$, mitogen-activated protein; $P K C$, protein kinase $C$; ORF2, open reading frame 2; NGFI-B, nerve growth factor-induced clone B; $S P A R C$, Secreted Protein Acidic and Rich in Cysteine. 
TABLE E2. Decreased expression after ischemia but preserved with cardioplegia

\begin{tabular}{|c|c|c|c|c|}
\hline Gene no. & $\begin{array}{l}\text { Ischemia } \\
\text { vs C }\end{array}$ & CP vs C & Gene product & Function/description \\
\hline \multicolumn{5}{|c|}{ Energy/metabolism } \\
\hline AF034577 & -3.7 & NC & Pyruvate dehydrogenase kinase (PDK4) & Acetyl CoA synthesis from pyruvate \\
\hline Z12158 & -3 & NC & PDH E1 $\alpha$ form 1 subunit & Acetyl CoA synthesis from pyruvate \\
\hline D13376 & -2.5 & -1.3 & Adenylate kinase 1 & ATP metabolism \\
\hline M27726 & -4.9 & NC & Phosphorylase (B-GP1) & Carbohydrate metabolism \\
\hline U20643 & -4 & -1.3 & Aldolase A & Carbohydrate metabolism \\
\hline AFFX-h & -3.5 & NC & Brain hexokinase & Carbohydrate metabolism \\
\hline D26393 & -3.5 & -1.6 & Type II hexokinase & Carbohydrate metabolism \\
\hline U20195 & -3.2 & NC & Phosphoglucomutase (Pgm1) & Carbohydrate metabolism \\
\hline M93401 & -2.1 & NC & Methylmalonate semialdehyde $\mathrm{DH}$ & Carbohydrate metabolism \\
\hline S50461 & -2.1 & NC & G protein $\alpha 12$ subunit & Carbohydrate metabolism \\
\hline D10952 & -3.5 & NC & Cytochrome $\mathrm{c}$ oxidase subunit $\mathrm{Vb}$ & $\begin{array}{l}\text { Electron transport/energy } \\
\text { production }\end{array}$ \\
\hline AA686031 & -3.5 & NC & Like NADH-ubiquinone oxidoreductase 75 & $\begin{array}{l}\text { Electron transport/energy } \\
\text { production }\end{array}$ \\
\hline M21476 & -2.5 & NC & lodothyronine 5-monodeiodinase (5-MD) & $\begin{array}{l}\text { Electron transport/energy } \\
\text { production }\end{array}$ \\
\hline AA685112 & -2.5 & NC & Like NADH-ubiquinone oxidoreductase 23 & $\begin{array}{l}\text { Electron transport/energy } \\
\text { production }\end{array}$ \\
\hline M24542 & -2.1 & NC & Rieske iron-sulfur protein & $\begin{array}{l}\text { Electron transport/energy } \\
\text { production }\end{array}$ \\
\hline Y17295 & -3 & NC & 1-Cys peroxiredoxin & FA metabolism \\
\hline AB005743 & -2.8 & NC & CD36 antigen & FA metabolism \\
\hline AB010429 & -2.6 & NC & Acyl-CoA hydrolase-like protein & FA metabolism \\
\hline X98225 & -2.6 & NC & Gastrin-binding protein & FA metabolism \\
\hline AF047707 & -2.6 & -1.3 & UDP-glucose:ceramide glycosyltransferase & FA metabolism \\
\hline AF063302 & -2.3 & NC & Carnitine palmitoyltransferase $\mathrm{I} \beta$ & FA metabolism \\
\hline E03344 & -2.1 & NC & Peroxisome-forming factor & FA metabolism \\
\hline D44481 & -2.3 & NC & Crk II adaptor protein & Glucose transport/adapter protein \\
\hline D10853 & -2.3 & NC & Amidophosphoribosyltransferase & Glutamine metabolism \\
\hline L01793 & -2.3 & NC & Glycogenin & Glycogen synthesis \\
\hline D21869 & -2.6 & NC & Phosphofructokinase-M & Glycolysis \\
\hline J05571 & -2 & NC & S-adenosylmethionine synthetase & Metabolism \\
\hline M58364 & -2.3 & -1.9 & GTP cyclohydrolase I & Synthesis of cofactor $\mathrm{BH} 4$ \\
\hline AF034577 & -3.7 & NC & Pyruvate dehydrogenase kinase (PDK4) & Acetyl CoA synthesis from pyruvate \\
\hline \multicolumn{5}{|c|}{ Calcium regulation } \\
\hline X68191 & -3.5 & NC & Sodium-calcium exchanger & Calcium regulation \\
\hline U95157 & -2.5 & NC & Ryanodine receptor type II (RYR2) & Calcium regulation \\
\hline U48247 & -3.2 & NC & Protein kinase $\mathrm{C}$-binding protein enigma & Calcium channel binding \\
\hline L18889 & -2.3 & NC & Calnexin & Calcium binding \\
\hline X53363 & -2.1 & NC & Calreticulin & Calcium binding \\
\hline \multicolumn{5}{|c|}{ Immune/inflammatory } \\
\hline U45965 & -3.5 & -1.9 & Inflammatory protein-2 precursor & Immune/inflammatory \\
\hline X17053 & -3.0 & -1.9 & Immediate-early serum-responsive JE gene & Immune/inflammatory \\
\hline M92340 & -2.0 & -1.2 & Interleukin 6 signal transducer & Immune/inflammatory \\
\hline
\end{tabular}


TABLE E2. continued

\begin{tabular}{|c|c|c|c|c|}
\hline \multicolumn{3}{|c|}{ Ischemia } & Gene product & Function/description \\
\hline AF029240 & -2.0 & -1.9 & MHC class Ib RT1.S3 (RT1.S3) & Immune/inflammatory \\
\hline \multicolumn{5}{|c|}{ Cytoprotective-ischemia/IPC/stress } \\
\hline M94454 & -2.1 & NC & $\begin{array}{l}\text { Serine-threonine protein kinase } \\
\text { (Map3k8) }\end{array}$ & Stress response \\
\hline U13396 & -9.2 & -1.5 & Protein-tyrosine kinase (JAK2) & Stress response \\
\hline U91847 & -7.5 & $\mathrm{NC}$ & $\begin{array}{l}\text { p38 Mitogen-activated protein } \\
\text { kinase }\end{array}$ & Stress response \\
\hline M18331 & -2.3 & -1.9 & Protein kinase $C \epsilon$ & Stress response \\
\hline J05181 & -7 & -1.4 & $\gamma$-Glutamylcysteine synthetase & $\begin{array}{l}\text { Glutathione synthesis/oxidative } \\
\text { stress }\end{array}$ \\
\hline X02904 & -2.3 & -1.4 & $\begin{array}{l}\text { Glutathione S-transferase P } \\
\text { subunit }\end{array}$ & $\begin{array}{l}\text { Glutathione synthesis/oxidative } \\
\text { stress }\end{array}$ \\
\hline J03914 & -2 & -1.3 & $\begin{array}{l}\text { Glutathione S-transferase } \mathrm{Yb} \\
\text { subunit }\end{array}$ & $\begin{array}{l}\text { Glutathione synthesis/oxidative } \\
\text { stress }\end{array}$ \\
\hline X15705 & -2.8 & NC & $\begin{array}{l}\text { Heat shock protein-related gene } \\
\text { hst70 }\end{array}$ & Heat shock/chaperone \\
\hline AA848268 & -2.3 & NC & Similar to DnaJ protein homolog 2 & Heat shock/chaperone \\
\hline S75280 & -2 & NC & $\begin{array}{l}\text { 70-kd Heat shock protein } \\
\text { precursor }\end{array}$ & Heat shock/chaperone \\
\hline Y00497 & -2.3 & NC & MnSoD & Oxidative stress \\
\hline U63923 & -2.3 & NC & Thioredoxin reductase & Oxidative stress \\
\hline D14568 & -8 & NC & Calcineurin B & Ischemia \\
\hline AF075383 & -2.8 & NC & Suppressor of cytokine signaling 3 & Jak/STAT pathway \\
\hline AJ005984 & -2.8 & -1.5 & $\alpha$-Endosulfine & K(ATP) channel regulation \\
\hline AF048828 & -3.5 & $\mathrm{NC}$ & $\begin{array}{l}\text { Voltage-dependent anion channel } \\
\text { (VDAC) }\end{array}$ & Mitochondrial calcium transport/IPC \\
\hline J02722 & -2.5 & NC & Heme oxygenase & Cleaves heme/stress induced \\
\hline \multicolumn{5}{|c|}{ Transcription } \\
\hline M65251 & -3.5 & -1.9 & Hivep2 & Transcription \\
\hline$X 54686$ & -2.6 & -1.4 & pJunB & Transcription \\
\hline X54249 & -2.5 & -1.6 & Zinc finger protein AT-BP1 & Transcription \\
\hline M65149 & -2.3 & -1.7 & CELF & Transcription \\
\hline D37951 & -2.3 & -1.5 & $\begin{array}{l}\text { MIBP1 (c-myc intron binding } \\
\text { protein 1) }\end{array}$ & Transcription \\
\hline M55017 & -2.3 & $\mathrm{NC}$ & Nucleolin & Transcription \\
\hline X63369 & -2.3 & -1.5 & Zinc finger protein Tis 11 & Transcription \\
\hline AF009330 & -2.0 & $\mathrm{NC}$ & SHARP-2 & Transcription \\
\hline L14462 & -2.0 & NC & R-esp1 & Transcription \\
\hline L14463 & -2.0 & NC & R-esp2 & Transcription \\
\hline U51584 & -2.0 & NC & $\begin{array}{l}\text { Zinc finger enhancer-binding } \\
\text { protein } 2\end{array}$ & Transcription \\
\hline \multicolumn{5}{|c|}{ Plos } \\
\hline X53565 & -7.0 & NC & $\begin{array}{l}\text { Trans-Golgi network protein } \\
\text { TGN38 }\end{array}$ & Protein transport \\
\hline U64689 & -4.3 & NC & $\begin{array}{l}\text { Synaptotagmin interacting protein } \\
\text { zygin II }\end{array}$ & Protein transport \\
\hline $\mathrm{X} 12535$ & -2.6 & NC & Rab7 & Protein transport \\
\hline AF052596 & -2.3 & NC & SNAP-23 & Protein transport \\
\hline M83676 & -2.1 & NC & Rab12 & Protein transport \\
\hline X13905 & -2.1 & NC & Ras-related rab1B protein & Protein transport \\
\hline AF019043 & -2.0 & NC & Dynamin-like protein (DLP1) & Protein transport \\
\hline X92097 & -2.0 & NC & Coated vesicle membrane protein & Protein transport \\
\hline
\end{tabular}


TABLE E2. continued

\begin{tabular}{|c|c|c|c|c|}
\hline Gene no. & $\begin{array}{l}\text { Ischemia } \\
\text { vs C }\end{array}$ & CP vs C & Gene product & Function/description \\
\hline AF072935 & -2.0 & NC & Rab5 & Protein transport \\
\hline AF097593 & -2.6 & $\mathrm{NC}$ & $\mathrm{N}$-cadherin & Adhesion molecule \\
\hline L23088 & -2.1 & -1.5 & P-selectin & Adhesion molecule \\
\hline AF097593 & -2.0 & NC & Testicular N-cadherin & Adhesion molecule \\
\hline M84488 & -2.5 & -1.5 & Vascular cell adhesion molecule 1 & Adhesion molecule \\
\hline L20913 & -3.5 & $\mathrm{NC}$ & $\begin{array}{l}\text { Vascular endothelial growth factor } \\
\text { form } 3\end{array}$ & Angiogenesis \\
\hline X14232 & -2.5 & NC & Heparin-binding growth factor 1 & Angiogenesis \\
\hline M32167 & -2.3 & NC & Glioma-derived VEGF & Angiogenesis \\
\hline U93306 & -2.5 & NC & VEGF receptor-2/FLK-1 & Angiogenesis \\
\hline AF004811 & -4.0 & NC & Moesin & Cytoskeletal \\
\hline AF053768 & -3.2 & NC & Cortactin-binding protein CBP90 & Cytoskeletal \\
\hline AFFX-ba & -2.8 & NC & Cytoplasmic $\beta$-actin & Cytoskeletal \\
\hline AFFX & -2.1 & NC & $\beta$-Actin & Cytoskeletal \\
\hline S74572 & -3.0 & NC & $\begin{array}{l}\mathrm{Mg}^{2+} \text {-dependent protein } \\
\text { phosphatase } \beta\end{array}$ & $\mathrm{Mg}^{2+}$-dependent phosphatase \\
\hline S90449 & -3.0 & $\mathrm{NC}$ & Protein phosphatase $2 \mathrm{C}$ isoform & $\mathrm{Mg}^{2+}$-dependent phosphatase \\
\hline AF071204 & -4.0 & -1.7 & Kit ligand 1 precursor & Stem cell factor \\
\hline M11794 & -3.7 & -1.9 & $\begin{array}{l}\text { Metallothionein } 2 \text { and } \\
\text { metallothionein } 1\end{array}$ & Zinc homeostasis \\
\hline AJ223083 & -12.1 & NC & Retinoic acid X receptor $\gamma-1$ & Growth and development \\
\hline M25350 & -3.2 & NC & cAMP phosphodiesterase (PDE4) s & cAMP-mediated pathways \\
\hline S77528 & -3.0 & NC & C/EBP-related transcription factor & Apoptosis \\
\hline AB000362 & -3.0 & NC & Cold-inducible RNA-binding protein & Cold response \\
\hline U77829 & -3.0 & -1.4 & Gas-5 growth arrest homolog & Growth arrest \\
\hline X60212 & -2.8 & NC & Ribosomal protein L17 & Translation \\
\hline L13407 & -2.6 & NC & CaM kinase II $\delta$ subunit & Smooth muscle cell migration \\
\hline U75920 & -2.5 & -1.6 & APC-binding protein EB1 & Cell cycle/microtubule binding \\
\hline D45247 & -2.5 & -1.2 & Proteasome subunit RCX & Ubiquitin protein catabolism \\
\hline D16308 & -2.3 & -1.6 & Cyclin D2 & Cell cycle \\
\hline M58040 & -2.3 & -1.4 & Transferrin receptor & Iron transport \\
\hline D90404 & -2.1 & NC & Cathepsin C & Protease \\
\hline Z83757 & -2.1 & NC & Growth hormone receptor & Growth \\
\hline X16043 & -2.1 & NC & Phosphatase 2A catalytic subunit $\alpha$ & Phosphatase \\
\hline D00092 & -2.0 & NC & 70-kd mitochondrial autoantigen & Autoantigen \\
\hline X77934 & -2.0 & NC & Amyloid precursor-like protein 2 & Amyloid secretion \\
\hline X99337 & -2.0 & $\mathrm{NC}$ & Glycoprotein 55 & Glycoprotein \\
\hline E05646 & -2.0 & -1.2 & $\begin{array}{l}\text { Hippocampal choline neuropeptide } \\
\text { HCNP }\end{array}$ & Phosphatidyl ethanolamine binding \\
\hline U61373 & -2.0 & NC & Proteinase-activated receptor 2 & G protein signal transduction \\
\hline D84477 & -2.0 & NC & RhoA & Ras-related/growth factor binding \\
\hline M74494 & -2.0 & 1.2 & $\begin{array}{l}\text { Sodium/potassium ATPase } \alpha-1 \\
\text { subunit }\end{array}$ & $\mathrm{Na} / \mathrm{K}$ regulation \\
\hline U50842 & -2.0 & -1.3 & Ubiquitin ligase (Nedd4) & Protein modification \\
\hline
\end{tabular}

Values represent fold change. Negative designates decrease. $C$, Control; $C P$, cardioplegia; $N C$, no change; $C o A$, coenzyme $A ; P D H$, pyruvate dehydrogenase; $A T P$, adenosine triphosphate; $D H$, dehydrogenase; $N A D H$, nicotinamide adenine dinucleotide; $F A$, fatty acid; UDP, uridine diphosphate; $G T P$, guanidine triphosphate; $B H 4$, tetrahydrobiopterin; $M H C$, major histocompatibility complex; $I P C$, ischemic preconditioning; $M n S o D$, manganese superoxide dismutase; $K(A T P)$, ATP-sensitive potassium channel; $A T-B P 1$, antitrypsin binding protein 1; CELF, CUG-BP and ETR-3 like factor; SHARP-2, split- and hairy-related protein-2; SNAP-23, synaptosomal-associated protein-23 kD; VEGF, vascular endothelial growth factor; $c A M P$, cyclic adenosine monophosphate; $A P C$, adenomatous polyposis coli; $A T P a s e$, adenosine triphosphatase. 
TABLE E3. Changed expression with both ischemia and cardioplegia

\begin{tabular}{|c|c|c|c|c|}
\hline \multirow[b]{2}{*}{ Gene no. } & \multicolumn{4}{|l|}{ Ischemia } \\
\hline & vs C & CP vs C & Gene product & Function/description \\
\hline \multicolumn{5}{|c|}{ Energy/metabolism } \\
\hline D87240 & -5.3 & -4.6 & Fructose-6-phosphate 2-kinase & Carbohydrate metabolism \\
\hline AF047707 & -2.0 & -2.0 & UDP-glucose:GlcT & Lipid transport and metabolism \\
\hline \multicolumn{5}{|c|}{ Immune/inflammatory } \\
\hline U17035 & -7.5 & -5.3 & mob-1 & Inflammatory/immune response \\
\hline E02468 & -7.0 & -2.1 & TNF & Inflammatory/immune response \\
\hline M80367 & -6.1 & -2.6 & Guanylate-binding protein 2 & Inflammatory/immune response \\
\hline Y07704 & -5.3 & -2.8 & BEST5 & Inflammatory/immune response \\
\hline M98820 & -4.3 & -4.0 & Interleukin $1 \beta$ & Inflammatory/immune response \\
\hline M34253 & -4.3 & -2.6 & IRF-1 & Inflammatory/immune response \\
\hline D00403 & -4.0 & -3.0 & Interleukin $1 \alpha$ & Inflammatory/immune response \\
\hline U68272 & -4.0 & -2.3 & Interferon $\gamma$ receptor & Inflammatory/immune response \\
\hline U06434 & -3.7 & -2.6 & MIP-1 $\beta$ & Inflammatory/immune response \\
\hline AF030358 & -3.7 & -2.3 & Chemokine CX3C & Inflammatory/immune response \\
\hline$X 52711$ & -3.5 & -4.0 & Mx1 protein & Inflammatory/immune response \\
\hline X63594 & -3.5 & -2.6 & $\mathrm{RL} / \mathrm{IF}-1$ & Inflammatory/immune response \\
\hline L00981 & -3.2 & -2.1 & TNF- $\beta$, TNF- $\alpha$ & Inflammatory/immune response \\
\hline U22414 & -2.3 & -2.1 & Inflammatory protein- $1 \alpha$ & Inflammatory/immune response \\
\hline \multicolumn{5}{|c|}{ Cytoprotective-ischemia/IPC/stress } \\
\hline AF055714 & 4.6 & 2.3 & Hypertension-reg vasc factor-1C-4 & Stress response \\
\hline L16764 & 4.6 & 4.9 & Heat shock protein 70 (HSP70) & Stress response \\
\hline \multicolumn{5}{|c|}{ Transcription } \\
\hline U18314 & 3.0 & 2.3 & Thymopoietin & Transcription \\
\hline AF015953 & 3.2 & 2.1 & aryl hydrcrbn recept nucl translctr & Transcription \\
\hline L23148 & 9.8 & 3.5 & Inhibitor of DNA binding 1 & Transcription, angiogenesis \\
\hline \multicolumn{5}{|l|}{ Other } \\
\hline L2552 & -7.0 & -2.6 & E-selectin (ELAM-1) & Adhesion molecule \\
\hline D00913 & -4.3 & -2.1 & Intercellular adhesion molecule 1 & Adhesion molecule \\
\hline X63722 & -3.2 & -2.0 & Vascular cell adhesion molecule 1 & Adhesion molecule \\
\hline AJ011969 & -3.5 & -2.8 & Growth differentiation factor 15 & TGF- $\beta$ signaling \\
\hline$X 57523$ & -2.8 & -2.1 & mtp1 & Iron transport \\
\hline AFFXbbm & 2.0 & 2.0 & 7,8-Diamino-pelargonic acid & Biotin synthesis proteins \\
\hline U17604 & 3.0 & 2.1 & Reticulon 1 & Endocytosis \\
\hline U78102 & 3.5 & 2.3 & krox20 & Growth and development \\
\hline L26292 & 4.6 & 3.7 & FSH-regulated protein & Follicle-stimulating hormone related \\
\hline AF036548 & 4.6 & 3.7 & RGC-32 & Response gene to complement 32 \\
\hline M26686 & 5.3 & 4.0 & Carboxyl methyltransferase & Protein modification \\
\hline L19998 & 7.0 & 4.0 & Minoxidil sulfotransferase & Steroid metabolism \\
\hline
\end{tabular}

Values represent fold change. Negative designates decrease. $C$, Control; $C P$, cardioplegia; UDP, uridine diphosphate; TNF, tumor necrosis factor; $B E S T 5$, bone-expressed sequence tag 5 ; IRF-1, interferon regulatory factor-1; $M I P-1 \beta$, macrophage inflammatory protein-1 $\beta$; $R L / I F-1$, nuclear factor of dappa light chain gene enhancer in B-cells inhibitor, alpha; $F S H$, follicle stimulating hormone; $R G C$-23, response gene to complement 32. 